\title{
Resgate do Artefato da Cabaça na Terra Paulista Caipira, sua Ancestralidade e Interlocução Contemporânea por meio do Design e Território: Um Ensaio Teóricom
}

\author{
Camila Ferreira de Oliveira Rocha ${ }^{1}$; \\ Rosinei Batista Ribeiro²; \\ Adilson da Silva Mello ${ }^{3}$
}

resumo:

Em um mundo globalizado, os territórios se tornam porosos aos valores políticos, econômicos, sociais e culturais de outros espaços geográficos, o que os fazem reproduzir as expressões massificadas e enfraquecer suas identidades, hábitos e costumes, inclusive a produção de artefatos tradicionais. 0 fenômeno ocorre no território caipira paulista, área desta pesquisa, localizada na Sub-região 4 da Região Metropolitana do Vale do Paraíba e Litoral Norte, também chamado de Vale Histórico. Em meio a tantas referências externas, como resgatar a identidade do território caipira, seus saberes e fazeres na contemporaneidade? É possível realizar o resgate de um artefato local que perdeu espaço para os produtos industrializados? Este artigo tem como objetivo realizar um ensaio teórico sobre o resgate do artefato proveniente do fruto cabaça, sua relação ancestral com a identidade, cultura e território e a sua interlocução contemporânea, pois o mesmo se desvinculou de sua origem e precisa de um posicionamento estratégico. Assim, a revisão bibliográfica também aborda a área do Design e Território, que, estrategicamente, cria um diálogo entre a tradição e inovação, para fortalecer a identidade e imagem do território, para agregar valor aos produtos locais e para estimular a geração de emprego e renda. Somado aos estudos sobre a produção da cabaça em outras regiões do país, é possível refletir sobre uma futura aplicação na área desta pesquisa, rica em histórias, culturas e etnias que formam uma base para o desenvolvimento de uma gama de produtos locais, produzidos com recursos naturais que precisam ser explorados de maneira sustentável juntamente com a valorização de seus patrimônios.

\section{palavras-chave:}

design e território; fruto cabaça; valorização de identidades locais; artefatos

\footnotetext{
${ }^{1}$ Link do lattes http://lattes.cnpq.br/8980498077169820

${ }^{2}$ Link do lattes http://lattes.cnpq.br/5938003791536092

${ }^{3}$ Link do lattes http://lattes.cnpq.br/4758034136465394

[i] O presente artigo é resultante da pesquisa do Programa de Pós Graduação (PRPPG) do Mestrado em Desenvolvimento, Tecnologias e Sociedade - DTecS da Universidade Federal de Itajubá - UNIFEI.
} 


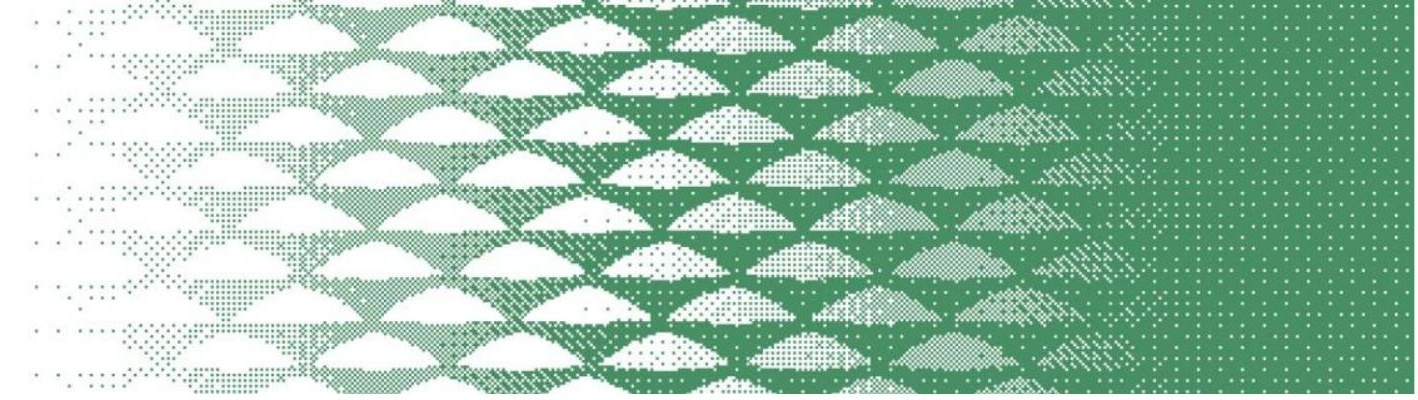

Espaço reservado para organização do congresso.

\section{Ensaio Teórico}

\subsection{Ancestralidade do fruto cabaça na terra paulista caipira}

A origem da cabaça continua sendo um enigma para os estudiosos, contudo, Segundo Cancelier e David (2020), a África é considerada a região ancestral, de aproximadamente de 250 mil anos. Há registros em outras civilizações em diferentes continentes como Ásia e, posteriormente, o continente Americano, que compartilha um ancestral com os frutos africanos entre de 60.000 a 103.000 anos. A comprovação genética se deu pela modelagem da deriva oceânica (Figura 1), mostrando que as africanas selvagens, muito leves, teriam boiado e percorrido o Oceano Atlântico, sendo que os cruzamentos com o Novo Mundo deu-se entre a latitude $20^{\circ} \mathrm{S}$ e do equador em menos de um ano, o que mostra a resistência da cabaça e suas sementes na período de flutuação no mar.

Whitacker (1971, apud Trevisol, 2015, p. 13) reforça a mesma dispersão oceânica da África para a região Neotropical, que abrange o México até a Argentina, incluindo o todo o território brasileiro (IBGE, 1992, p. 15).

Figura 1: Dispersão oceânica da cabaça do Velho para o Novo Mundo e suas interlocuções culturais e sociais

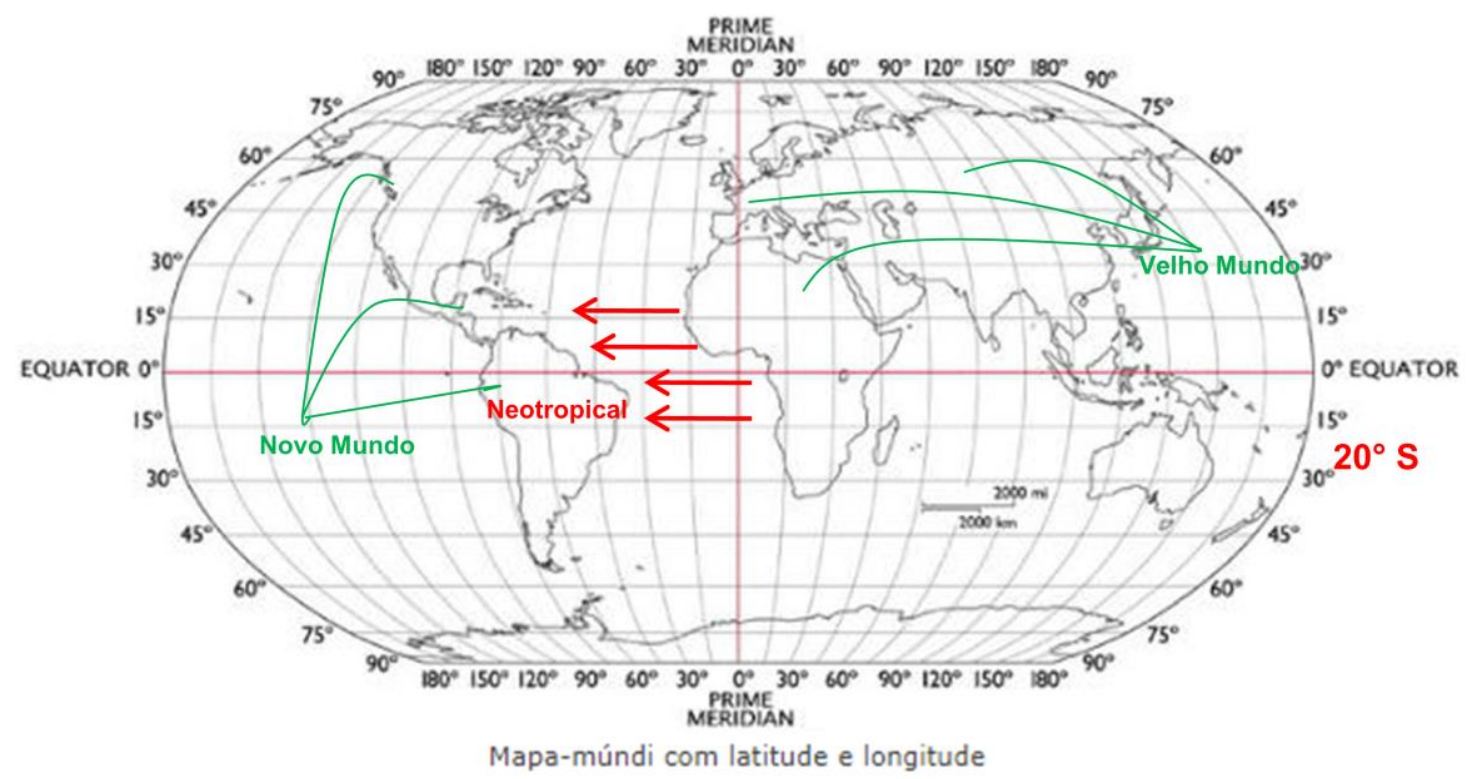

Fonte: os autores (2021) adaptado de Phaneron Soft (2021)

Foi verificado que a cabaça é a única planta com distribuição global pré-colombiana e uma das primeiras plantas domesticadas. A sua utilização por seres humanos no Novo Mundo se deu há 12 mil anos, sendo o México o suposto local inicial de domesticação e dispersão do fruto, uma vez que os nativos eram nômades e se deslocavam na busca de alimentos, que eram armazenados e transportados pelos artefatos da cabaça (KISTLER apud CANCELIER E DAVID, 2020, p. 52). 


\section{JOP \\ DESIGN \\ de Pós-Graduação em Design - UFMA}

No Brasil, mais especificamente na região do Vale do Paraíba Paulista, área deste estudo, os registros da utilização da cabaça são encontrados nos relatos dos viajantes portugueses,que tiveram contato com os índios Puris, como o Príncipe Maximiliano, que realizou a viagem do Rio de Janeiro a Bahia e descreveu alguns dos artefatos dos habitantes como "as tigelas feitas com frutos da crescentia cujete, ou pequenas cabaças". (REIS, 1979, p. 84)

A terra abundante aliada à necessidade e criatividade leva o nativo a criar e experimentar os diversos materiais naturais, que, quando aprimorados de acordo com sua forma e resistência, serviam para diferentes finalidades.

O uso dos vasilhames feitos com os frutos se estendeu nas longas jornadas dos bandeirantes e tropeiros e, dentre os objetos de cozinha utilizados, também constava a cuia de meia cabaça (MARINS, 2008, p. 120).

A trajetória da cabaça no Vale ultrapassa gerações, etnias e culturas, pois, além de servir de utensílio doméstico para os nativos e, depois, aos portugueses e escravos africanos, também adentra nos espaços domésticos das famílias caipiras, que se caracteriza pela união dos povos citados anteriormente.

Segundo Francisco (2008, p. 31, grifo nosso) os caipiras faziam"gamelas de raiz de figueira, vasilhas de porunga, potes de barro, colheres de pau, fruto do "saber fazer" local.É a tralha doméstica. Constroem-se monjolos, pilão para fabrico de carne-seca e farinha de mandioca; tecnologia aborígine". É importante lembrar que o fruto em questão apresenta diferentes nomes, como a porunga, porongo ou cabaça, ambos são frutos do gênero Lagenaria, da família das cucurbitáceas, uma vegetação rasteira (TREVISOL, 2015, p. 11 a 13).

Contudo, pode se observar que, após o período das culturas de subsistência e especialmente para o açúcar, no século XVIII até meados do XIX, a partir do século XIX, com a chegada do café, houve um grande contraste dos ambientes domésticos entre os ricos fazendeiros e os pobres dos outros extratos da população paulista, bem como os objetos (MARINS, 2008, p. 155 a 157).

Com a chegada do trem, da importação do luxo e a imigração nos séculos XIX e início do XX, para Marins (2008,p. 133), houve "o indício de um processo de absorção e reelaboração de referenciais europeus que seria constante na vida paulista". A começar pelos novos hábitos de consumo, devido à agilidade e segurança do transporte, que possibilitou a oferta de objetos manufaturados e industrializados em substituição aos mais rústicos. As transformações "modernas" da sociedade, devido à consolidação do sistema capitalista, evidenciaram os sintomas da crise social e cultural, que se estendem até a contemporaneidade.

Do mesmo modo, Marins (2008 p. 154) diz que com a chegada dos novos artefatos de luxo, os objetos mais simples improvisados com frutos não desapareceram das moradas mais ricas, apesar de não constarem nos inventários pelo seu valor ínfimo e, continuaram comuns nas moradas mais modestas, ao afirmar que o reinado do café iniciou "nas xícaras, copos, canecas e cuias dos paulistas". (MARINS, 2008, p. 133, grifo nosso).

Além disso, com a chegada da industrialização no país, os verdadeiros criadores da arte do interior foram arrastados para a cafeicultura e indústrias, deixando de lado os ofícios do campo, e, consequentemente, a produção artesanal e toda a sua diversidade (SANTOS, 2008, p. 121).

O capitalismo, a industrialização e sua produção em massa, distanciou a autonomia e a criatividade do produtor artesão, devido ao processo de alienação do trabalho, onde o produtor deixou de atuar nas diversas etapas que envolvem a produção, e também deixou de lado o seu conhecimento e a sua capacidade produtiva, que foi tomada pela empresa. Assim, houve uma especialização do trabalho compensado por um salário, que não valia a riqueza do trabalho gerado.

O resultado foi a extinção de vários ofícios que desapareceram junto com seus mestres, que muitas vezes não conseguiam sobreviver dignamente de seu trabalho em virtude dessa acirrada concorrência e da própria desorganização do setor artesanal. (SANTOS, 2008, p. 121) 


\section{JOP 21
DESIGN

Para o autor, o público consumidor passou a ter opção de compra, o que fez com que os artesãos se apropriassem de elementos do produto industrial para produzir algo competitivo e mais ao gosto do turista. Assim, eles alteraram as formas, cores, simbologia, processos, etc, ou seja, descaracterizaram o artesanato, para a sua sobrevivência e para a preferência do cliente, e mesmo assim, longe dos grandes centros (SANTOS, 2008, p. 121).

Vale lembrar que, na Sub-região 4, área desta pesquisa, devido à decadência do café, ao solo arrasado e o fim da escravidão, somado ao posterior distanciamento com a Rodovia Presidente Dutra, que proporcionou a implantação de diversas indústrias nas outras sub-regiões do Vale do Paraíba, para Santos (2008, p. 122) o artesanato se manteve intocado e se tornou um reduto tradicional da produção artesanal. Segundo o Programa do Artesanato Brasileiro (PAB) o artesanato é uma produção resultante de técnicas, saberes e fazeres combinados os meios de produção, que expressam identidade cultural, criatividade, qualidade e habilidade, e matérias-primas, que podem ser de origem animal, vegetal ou mineral, e que são tratadas e transformadas por processos químicos ou físicos e podem ser utilizadas no estado natural ou manufaturado (BRASIL, 2018).

Segundo Santos (2008, p. 117), a variedade de técnicas empregadas na arte pode ser a característica mais marcante da região, pois não há uma específica estabelecida no território, há uma miscigenação de referências e valores, que cria uma identidade local, uma vocação territorial. Aos poucos a diversidade de peças paulistas contemporâneas passam a ser utilizadas pelos arquitetos e designers nos ambientes, "num movimento oposto ao que se iniciara em princípios do século XIX. Ou seja, o artesanato se renova e reconquista as áreas sociais da casa, de onde, aliás, nunca deveria ter saído". (SANTOS, 200, p. 122)

Ainda assim, muitas técnicas e artefatos da Sub-região 4 se perderam ou diminuíram a produção, devido à concorrência com os artigos industrializados. Outra questão é a falta de pesquisas científicas, divulgação, valorização e aproveitamento do artefato, como é o caso da cabaça, objeto desta pesquisa, que precisa passar por um processo de resgate e ressignificação para se posicionar no mundo contemporâneo.

\subsection{Estratégias do Design e Território para a Valorização de Produtos Locais}

É nítido o efeito dos processos globais que abalam as identidades locais, como acontece na terra paulista caipira. Mas, também, não se pode negar o fenômeno, pois a sociedade se transforma no tempo, bem como seus hábitos e costumes, que se moldam com os avanços da ciência e da tecnologia, além de toda a diversidade cultural externa que adentra o território.

É um desafio encontrar oportunidades nas situações de equilíbrio na relação local-global, no que se refere à qualidade de vida, à valorização e respeito da diversidade e ecossistema e aos modelos de produção e consumo (KRUCKEN, 2009, p. 37).

O desafio também é colocado por Moraes (2010, p. 14) no Caderno de Estudos Avançados em Design Identidade, pois o design age transversalmente, com áreas menos objetivas e exatas, passando para a área humana e social, portanto, se faz necessário potencializar as identidades do território e sua gente.

Das controvérsias, provocações e desafios do sistema, pode-se extrair uma ocasião favorável ao surgimento de novos cenários criativos e alternativos, para fortalecer a diversidade e as identidades, que até então se encontram desvinculadas de sua origem. "Essa é a herança perversa que nos desafia a pensar em dinâmicas de desenvolvimento mais includentes e mais redutora dos desequilíbrios regionais". (LAGES; BRAGA; MORELLI, 2004)

Neste sentido, o design sai do campo estático de representação e entra no campo da transformação. O design precisa mudar e caminha para a sustentabilidade, em um terreno fértil, pois há uma necessidade de mudanças nos modos de vida e nos sistemas produtivos, porém, deve-se ter cautela em relação ao ritmo desta mudança, pois a transformação deve incorporar a área tecnológica e a social, para valorizar os recursos locais em benefícios das comunidades (MANZINI e MERONI, 2009, p. 14).

O design precisa se tornar ativo com a quebra de barreiras e contribuição com as novas relações que se projetam nos territórios. Deve ser uma ferramenta estratégica de inovação e criação nas 


\section{JOP

sociedades contemporâneas. Assim, ele promove redes locais e globais e cria um diálogo entre tradição e os avanços tecnológicos, em uma interação equilibrada.

Com isso, o design deve fomentar a valorização sustentável dos recursos e produtos locais, que, para Krucken (2009, p. 17), são "manifestações culturais fortemente relacionadas com o território e a comunidade que o gerou". O design também pode valorizar os produtores e o seu trabalho, aprimorando os processos produtivos, criando a geração de renda e diminuindo desigualdades (PEREIRA, 2012).

Para Belchior e Ribeiro (2017) o design é capaz de gerar significados distintos aos produtos, para torná-los mais atraentes na sociedade. Isso também inclui repensar a sua aplicação e a sua relação com o usuário, atribuindo, assim, novos conceitos e percepções, "que ultrapassam o valor econômico dos objetos, gerando um valor especial, um novo significado". (BELCHIOR e RIBEIRO, 2017)

Neste sentido, o design tem um papel importante para atribuir novos signos aos artefatos, onde "ressignificar é proporcionar um novo sentido ao objeto, alterando seu conceito, sua percepção ou interpretação original. É tornar o objeto coerente para o sujeito, sob novo ponto de vista, transformando-o para o contexto vigente". (BELCHIOR e RIBEIRO, 2017)

Assim, resgatar o artefato da cabaça para criar uma identidade multicultural, que já se estabelece na região, é uma estratégia do design, pois a matéria-prima do artefato é um fruto, e está indissoluvelmente vinculado ao território onde é cultivado, carrega em sua a história do local e do povo (NIJELISKI, 2015, p. 28).

Para Krucken (2009) "o design pode contribuir significativamente neste contexto, buscando formas para tornar visível à sociedade a história por trás dos produtos". Pelo mesmo viés, Belchior e Ribeiro (2017) afirma, que, hoje, o objeto é mais do que a sua manifestação tangível e material, ele reflete signos e narrativas que atribuem uma diversidade de funções e experiências.

Latour (2012) afirma que o artefato não é inerte, ele é responsável pela ação do ser humano, ou seja, ele define as práticas sociais e os costumes. Logo, o artefato traz consigo a identidade local e uma narrativa genuína de trechos de acontecimentos repletos de significados poéticos e imaginativos e que formam o alicerce da vida em sociedade.

O Design e Território, deve, portanto, criar um diálogo entre os fazeres tácitos e usos ancestrais da cabaça com as inovações e tendências contemporâneas. Para Krucken (2009, p. 103) o design deve contribuir e "apoiar" a produção local, valorizando o saber-fazer tradicional com a incorporação à partir do uso de tecnologias, porém, sem mascarar as múltiplas faces que o artefato irá possuir. Para a autora, deve-se manter as características essenciais somadas às inovações, para tornar o produto mais atraente. Nesta mesma vertente, Celaschi (2010, p. 51) reforça a pluralidade de identidades que o design contemporâneo assume, onde as origens e todos significados relacionados ao artefato irão dividir o espaço com os novos traços e atender a demanda atual com a funcionalidade e estética.

\subsection{Fruto Cabaça: material e processos a serem explorados na região}

O Cultivo da cabaça é muito explorado em diversas regiões do país e trazem identidade ao território, sendo que cada uma atribui funções e signos de acordo com a sua cultura. No Sul, o fruto dá origem ao recipiente do chimarrão, e no Centro-Oeste, o tereré. No Nordeste, além de recipiente para armazenamento de alimentos, bebidas e roupas, o fruto serve como uma importante unidade de medida nas tradicionais feiras, além de usos medicinais (CARVALHO;CALHEIROS;OLIVEIRA, 2007, p. $13)$.

Contudo, na região Sudeste, mais especificamente na região do Vale Histórico, não há registros atuais da cultura e seus artefatos, mas a sua aplicação contemporânea pode se basear nas produções de outros territórios, como o Rio Grande do Sul, onde a cultura é mais sólida e enraizada. Mesmo que os autores gaúchos relatem a escassez de estudos na área e falta de difusão no país, as técnicas tradicionais e especializadas devem ser analisadas e aplicadas em outras localidades, pois são referências na área.

$\mathrm{Na}$ análise é necessário levantar os aspectos morfológicos e caracterização do fruto, que podem ser empregados pelos habitantes da região caipira, para a futura geração de renda. 


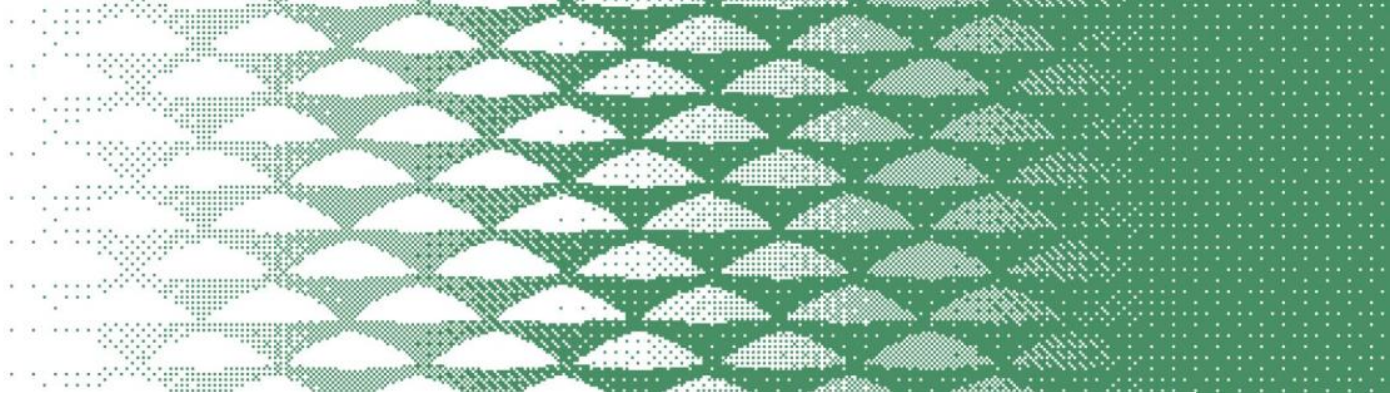

Segundo Trevisol (2013, p.19) o porongo (cabaça) possui uma casca dura e muito resistente, por isso, é classificado na botânica como uma baga do tipo pepo. A casca, que pode ter diferentes tons de marrom, guarda as sementes até o seu estágio maduro, onde as sementes são liberadas no ambiente. Portanto, "o fruto é indeiscente e quanto à forma pode ser alongado, cilíndrico, curvado, largo, oblongo, redondo, redondo-achatado e cônico". (TREVISOL, 2015, p.19)

Tabela 1: Porongos encontrados no estado do Rio Grande do Sul e suas nomenclaturas destacadas no formato regionais

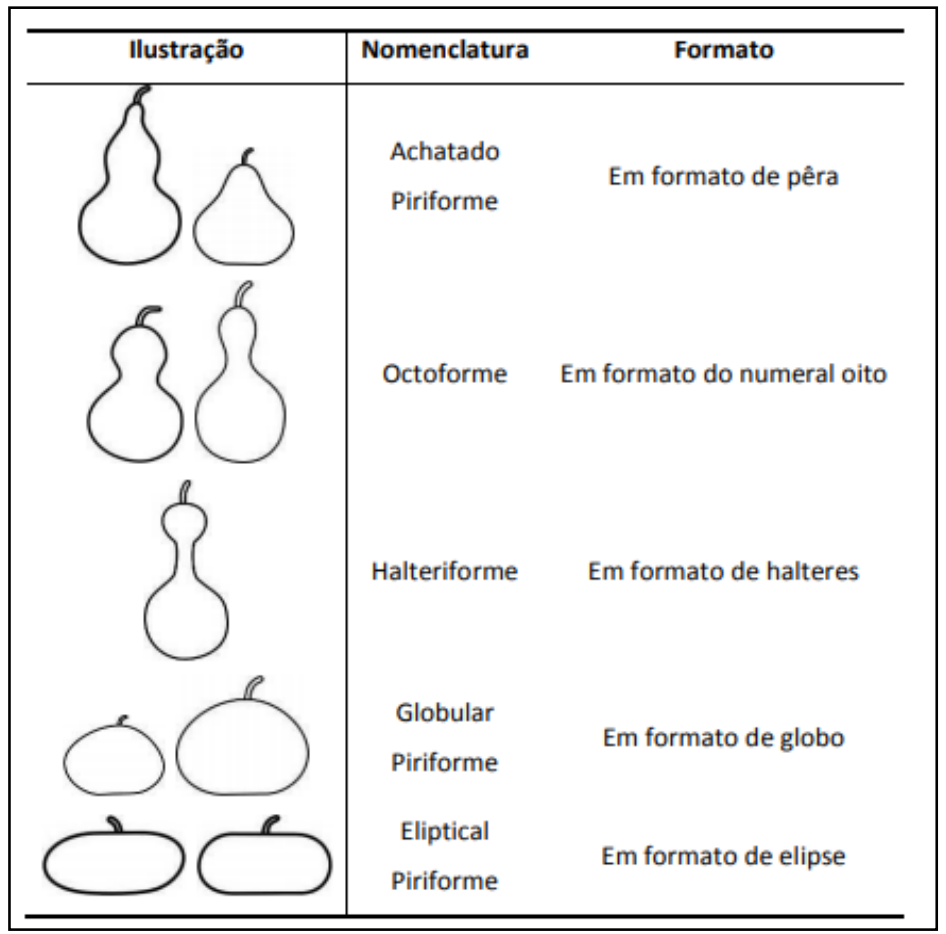

Fonte: Adaptado de Silva et al.,2002

Trevisol (2013, p.36) realizou um estudo sobre a qualidade morfológica, como a espessura final da cuia, medida em três pontos equidistantes que devem apresentar o mínimo de $10 \mathrm{~mm}$. Para Trevisol $(2015$, p. 52) "o casco mais espesso é fundamental para preservar, por mais tempo, a temperatura da infusão no chimarrão, qualidade a ser buscada e mantida nas seleções". O comprimento e os diâmetros do casco também são analisados.

Nijeliski (2015, p. 53 e 54) aponta que, após a seleção dos frutos, é necessário potencializar a sua utilização como um recipiente de bebidas, no caso o chimarrão. É realizado a limpeza externa e interna, para a retirada dos resíduos secos. Na sequencia é feito a retificação da superfície através do lixamento, principalmente na parte interna, que possui irregularidades.

Para a alteração da cor da superfície, uma das técnicas utilizadas pelas indústrias é a aplicação de ácido nítrico com a esponja e posterior aquecimento com o maçarico. Segundo Politis (2004, apud, Nijelisk, 2015, p. 48) os africanos desenvolveram técnicas ancestrais de coloração com pigmentos naturais de folhas de milheto (cor rosa), com o índigo (cor azul) e o escurecimento (ambiente com fumos). Com essa referência, outros pigmentos poderão ser explorados, de acordo com os materiais naturais produzidos em cada região. 


\section{JOP \\ DESIGN \\ de Pós-Graduação em Design - UFMA}

Além da coloração, outros aspectos decorativos são inseridos na superfície do fruto, como os detalhes de grafismos citados por Nijeliski $(2015$, p. 51) à partir da pirogravura, entalhes e gravação à laser, que recebem uma camada de cera para o polimento final. Em relação aos motivos decorativos, na cultura inca, por exemplo, são criados desenhos e símbolos que representam o folclore local, um conhecimento que é passado de geração em geração e são usuais até hoje, uma tradição milenar (NIJELISKI e DUARTE, 2017, p. 5)

Nijeliski (2015, p. 30) realizou um estudo sobre a caracterização do material e a aplicação de tratamentos atóxicos para aumentar a sua durabilidade e facilitar a limpeza, pois se trata de uma matéria-prima orgânica, porosa internamente, que está suscetível a agentes externos que aceleram a sua degradação. "A parte interna da casca adquire características semelhantes à da madeira, e a casca externa, extremamente fina e lisa, torna-se impermeável". (NIJELISKI, 2015, p. 25)

A microtomografia computadorizada $(\mu \mathrm{CT})$ realizada por Nijelisk, Lago e Duarte $(2020, \mathrm{p}$. 33), é uma técnica de análise tridimensional utilizada para a caracterização da microestrutura das amostras coletada em Santa Maria - RS. Foi observado uma baixa condução térmica e densidade, além da alta absorção de água. Assim, é necessário trabalhar com a impermeabilização da peça. Nos experimentos de Nijeliski $(2015$, p. 124) a resina poliuretana à base de óleo de mamona se mostrou eficaz, atóxica e de baixo impacto ambiental, atingindo um nível de impermeabilização para a aplicação em recipientes de alimentos e bebidas, uma sugestão de sua pesquisa.

Todos os critérios citados acima visam garantir um fruto comercial para a produção da cuia gaúcha, contudo, devido a variabilidade genética, variabilidade de tecnologias empregadas na cultura, falta de informações técnicas e condições ambientais, o rendimento é pequeno e muitas cuias são descartadas e há um risco de "erosão genética" da espécie (TREVISOL, 2015, p. 10).

Apesar das peculiaridade do fruto, condições adversas e escassez de pesquisas científicas voltadas para o fruto, existe um conhecimento acumulado sobre o processo que é empírico, e que precisa ser analisado em cada região. Além disso, pelas propriedades que apresenta, segundo Nijeliski e Duarte (2017, p. 1) o material do fruto tem um potencial a ser explorado na aplicação de design de novos produtos, "para a produção recipientes para alimentos e bebidas, produtos e revestimentos isolantes e filtros". (NIJELISKI; LAGO; DUARTE, 2020, p. 33)

\section{Conclusão}

Com a revisão bibliográfica, constatou-se a presença e utilização da cabaça pelos povos que habitavam a região do Vale do Paraíba, indígenas, bandeirantes, tropeiros e famílias caipiras até o período da cafeicultura. Entretanto, o declínio da cafeicultura na região, abertura de novas estradas e o processo de industrialização foram fatores que impactaram na produção de diversos produtos artesanais, desde a utilização do material natural e rústico até o processo produtivo, que perderam espaço e visibilidade para os artigos industrializados. Neste ponto, percebe-se que a cultura caipira, expressa em artefatos, deixa de ter relevância para o seu povo, causando uma crise de identidade cultural.

Mesmo em regiões onde o cultivo e o uso da cabaça é uma tradição, os estudos especializados para aprimorar as técnicas e processos são escassos, e a situação é anda mais preocupante no Vale.

Portanto, os estudos na área do Design e Território são essenciais resgatar a identidade caipira na contemporaneidade e para auxiliar os produtores a se posicionarem no mercado.

Estabelecer o diálogo entre os fazeres tradicionais e a incorporação de tecnologias é uma maneira estratégica para a valorização do produto local e a comunidade que o gerou e para adequar o artefato às demandas atuais da sociedade, sem descaracterizá-lo ou distanciá-lo de sua origem.O processo é válido para que ele retorne ao patamar de outrora e crie raízes locais. Além de contribuir com a minimização dos impactos ambientais, uma vez que valoriza um produto tradicional de fonte renovável, evita desperdícios nos processos e aumenta os rendimentos. 
Abstract: In a globalized world, territories become porous to the political, economic, social and cultural values of other geographic spaces, which make them reproduce mass expressions and weaken their identities, habits and customs, including the production of traditional artifacts. The phenomenon occurs in the caipira territory of São Paulo, area of this research, located in Sub-region 4 of the Metropolitan Region of Vale do Paraíba and Litoral Norte, also called Vale Histórico. In the midst of external references, how to recover the identity of the country territory, its knowledge and actions in contemporary times? Is it possible to carry out or rescue a local artifact that has lost space for industrialized products? This article aims to carry out a theoretical essay on the rescue of the artifact from the gourd fruit, its ancestral relationship with identity, culture and territory and its contemporary interlocution, as it has become detached from its origin and the need for a strategic position. Thus, a bibliographic review also addresses the area of Design and Territory, which, strategically, creates a dialogue between tradition and innovation, to strengthen the identity and image of the territory, to add value to local products and to stimulate the generation of employment and income. In addition to studies on the production of gourd in other regions of the country, it is possible to reflect on a future application in the area of this research, rich in histories, cultures and ethnicities that form a basis for the development of a range of local products, available with resources natural resources that need to be exploited in a natural way with the enhancement of their heritage.

Keywords: design and territory; gourd fruit; valorization of local identities; artefacts

\section{Referências bibliográficas}

BRASIL. Programa de Artesanato Brasileiro, 2018. Disponível em:

HTTPS://WWW.IN.GOV.BR/MATERIA//ASSET_PUBLISHER/KUJRWOTZC2MB/CONTENT/ID/34932949/D O1-2018-08-01-PORTARIA-N-1-007-SEI-DE-11-DE-JUNHO-DE-2018-34932930. Acesso em: 02 de mai. 2021.

BELCHIOR, Camilo; RIBEIRO, Rita Aparecida da Conceição. Estruturando uma metodologia para analisar a ressignificação como ferramenta estratégica do design, Colóquio Internacional de Design, Belo Horizonte: 2017.

CANCELIER, Janete Weble; DAVID, Cesar. A trajetória histórica do porongo e a diversidade dos artefatos produzidos em diferentes espaços: a importância para a agricultura familiar de Santa Maria /RS, in: Geografia Ensino \& Pesquisa, vol. 24, Santa Maria: 2020.

CARVALHO, Luciana; CALHEIROS,Vera; OLIVEIRA, Vânia. da cabaça o Brasil: natureza, cultura e diversidade, Belo Horizonte: 2007.

CELASCHI, Flaviano. Caderno e Estudos Avançados em Design Identidade, EdUEMG. Barbacena: 2010. 
FRANCISCO, Luís Roberto. Terra Paulista: histórias, arte e costumes, Imesp. vol. 2, São Paulo: 2008.

IBGE. Instituto Brasileiro de Geografia e Estatística. Manual técnico d vegetação brasileira. Rio de Janeiro, n.1, 1992.

KRUCKEN, Lia. Design e território: valorização de identidades e produtos locais, Studio Nobel, São Paulo: 2009.

LAGES, V.; BRAGA, C.; MORELLI, G. Territórios em movimento, Brasília: Relume Dumará, 2004

LATOUR, Bruno. Reagregando o social, EDUFBA/Edusc, Bahia: 2012.

MANZINI, Ezio; MERONI, Anna. Design e território: valorização de identidades e produtos locais, Studio Nobel, São Paulo: 2009.

MARINS, Paulo César Garcez. Terra Paulista: histórias, arte e costumes, Imesp. vol. 2, São Paulo: 2008.

MORAES, Dijon. Caderno e Estudos Avançados em Design Identidade, EdUEMG. Barbacena: 2010.

NIJELISKI, Daniele Maehler. O porongo (lagenaria siceraria) como matéria-prima para a produção de recipientes: caracterização e impermeabilização, Porto Alegre:2015.

; DUARTE, Lauren da Cunha. Bottle gourd (Lagenaria siceraria) as an alternative of natural renewable source material in product design. Belo Horizonte: 2017.

; LAGO, Tatiana; DUARTE, Lauren da Cunha. Design, tecnologia e matérias-primas locais: uso da microtomografia na caracterização da microestrutura do porongo ( Lagenaria siceraria), Rrevista Design Tecnologia, Porto Alegre: 2020.

PEREIRA, Andréa Franco. Design para a sustentabilidade: melhoria de produtos e processos e valorização da identidade local, Revista Estudos em Design, vol. 20, Rio de Janeiro: 2012.

REIS, Paulo Pereira. O Indígena do Vale do Paraíba, Imesp. São Paulo:1979.

SANTOS, Roberto. Terra Paulista: histórias, arte e costumes, Imesp. vol. 3, São Paulo: 2008.

TREVISOL, Wolmar. A Cultura do Porongo, 2015.

2013. Morfologia e fenologia do porongo: produtividade e qualidade da cuia. Piracicaba: 